\title{
Inhibition of smooth muscle cell proliferation by adiponectin requires proteolytic conversion to its globular form
}

\author{
Melissa Fuerst ${ }^{1,3}$, Carla G Taylor ${ }^{1,2,3}$, Brenda Wright ${ }^{3}$, Leslee Tworek ${ }^{3}$ and Peter Zahradka ${ }^{1,2,3}$ \\ Departments of ${ }^{1}$ Human Nutritional Sciences and ${ }^{2}$ Physiology, University of Manitoba, Winnipeg, Manitoba, Canada R3T 2N2 \\ ${ }^{3}$ Molecular Physiology Laboratory, Canadian Centre for Agri-food Research in Health and Medicine, St Boniface Hospital Research Centre, 351 Tache Avenue, \\ Winnipeg, Manitoba, Canada R2H $2 \mathrm{~A} 6$ \\ (Correspondence should be addressed to P Zahradka at Molecular Physiology Laboratory, Canadian Centre for Agri-food Research in Health and Medicine, \\ St Boniface Hospital Research Centre; Email: peterz@sbrc.ca)
}

\begin{abstract}
Accelerated atherosclerosis is the primary cardiovascular manifestation of diabetes and correlates inversely with levels of circulating adiponectin, an anti-atherosclerotic adipokine that declines in diabetes. We therefore initiated a study to examine the mechanisms by which adiponectin, a hormone released from adipose tissue, influences the proliferation of vascular smooth muscle cells (SMCs). Addition of adiponectin to quiescent porcine coronary artery SMCs increased both protein and DNA synthesis and concurrently activated ERK1/2 and Akt. By contrast, globular adiponectin, a truncated form of this protein, exhibited anti-mitogenic properties as indicated by the inhibition of protein and DNA synthesis in SMCs stimulated with platelet-derived growth factor (PDGF). Whereas globular adiponectin did not stimulate
\end{abstract}

growth-related signal transduction pathways, it was able to block the PDGF-dependent phosphorylation of eukaryotic elongation factor 2 kinase, a regulator of protein synthesis. Proteolysis of adiponectin with trypsin, which produces globular adiponectin, reversed the growth-stimulating actions of the undigested protein. As the existence of globular adiponectin remains controversial, western blotting was used to establish its presence in rat serum. We found that globular adiponectin was detectable in rat serum, but this result was not obtained with all antibodies. The contrasting properties of adiponectin and its globular form with respect to SMC proliferation suggest that protection against atherosclerosis may therefore be mediated, in part, by the level of globular adiponectin.

Journal of Endocrinology (2012) 215, 107-117

\section{Introduction}

Adipokines are hormones that are secreted by adipose tissue. While several adipokines regulate appetite and energy expenditure (Trayhurn \& Bing 2006), the most abundant protein produced by adipocytes is adiponectin, a protein first identified by Scherer et al. (1995), which is inversely correlated with atherosclerosis (Lam \& Xu 2005). Adiponectin is a 244 amino acid $(30 \mathrm{kDa})$ protein also known as adipocyte complement-related protein or Acrp. This protein contains two domains (collagen-like region, complement C1q region) that show homology with the collagen superfamily, complement factors, and tumor necrosis factor- $\alpha$ (TNF- $\alpha$; Kadowaki \& Yamauchi 2005). The collagen-like region promotes the formation of distinct 180 and $360 \mathrm{kDa}$ multimers (Waki et al. 2003). Also low levels ( $\sim 5 \%$ of total adiponectin) of an $18 \mathrm{kDa}$ truncated form containing the complement $\mathrm{C} 1 \mathrm{q}$-like region, typically referred to as globular adiponectin, have been detected in vivo (Fruebis et al. 2001).

A causal link between adiponectin and vascular disease was first reported by Okamoto et al. (2002). In their study, adenovirus was used to express adiponectin at high levels in Apoe $e^{-1-}$ mice, and this treatment led to a decline in the number and size of atherosclerotic lesions in the aorta. These results, which have been subsequently confirmed by others (Yamauchi et al. 2003a,b, Li et al. 2007), may explain the abundant epidemiological data that show atherosclerotic disease is elevated under conditions where circulating adiponectin levels (Scherer et al. 1995) are significantly reduced, such as obesity and diabetes (Weyer et al. 2001). Furthermore, an elegant study by Clasen et al. (2005) has established a link between pharmacological agents capable of limiting progression of atherosclerotic disease (e.g. ACE inhibitors and PPAR agonists) and increased serum adiponectin. These data indicate that an intervention capable of elevating adiponectin levels will likely benefit cardiovascular health.

The evidence clearly supports a role for adiponectin in maintaining the health of cardiovascular tissues (Do et al. 2006, DeClercq et al. 2008). On the other hand, whether adiponectin is responsible for all the beneficial effects ascribed to this protein has not been elucidated. Fruebis et al. (2001) hypothesized that adiponectin is an inactive 
precursor and that globular adiponectin is the functionally relevant form of this hormone. This view, however, is not supported by evidence showing both forms of adiponectin bind and activate the adiponectin receptors AdipoR1 and AdipoR2 (reviewed in Kadowaki \& Yamauchi (2005)). As well, adiponectin and globular adiponectin independently elicit distinct biological responses in various tissues. For instance, both adiponectin and globular adiponectin inhibit atherosclerotic lesion formation in $A p o e^{-1-}$ mice (Okamoto et al. 2002, Yamauchi et al. 2003a,b) and activate AMPdependent protein kinase (AMPK) in the cells of responsive tissues (Yamauchi et al. 2002). On the other hand, globular adiponectin activates fatty acid oxidation in skeletal muscle but not liver, whereas adiponectin stimulates fatty acid oxidation in both tissues (Yamauchi et al. 2003a,b). Furthermore, the small quantity of globular adiponectin found in serum has made resolution of this issue difficult. It is important to note that there have been few direct comparisons between adiponectin and globular adiponectin under identical conditions. We therefore undertook to evaluate the effects of adiponectin and globular adiponectin on smooth muscle cell (SMC) proliferation. Our results indicate that their actions on SMCs are distinct. Furthermore, we establish by western blotting that globular adiponectin is present in normal rat serum, but its detection is dependent on the antibody being used.

\section{Materials and Methods}

\section{Materials}

Nunc tissue culture plates were obtained from VWR (Mississauga, ON, Canada), and culture media and fetal bovine serum were from Invitrogen. Radioisotopes were purchased from Perkin-Elmer. Platelet-derived growth factor (PDGF)-BB was from Peprotech (Dollard des Ormeaux, QC, Canada), while recombinant (bacterially expressed) adiponectin and globular adiponectin were purchased from Alexis Biochemicals (Farmingdale, NY, USA). Acetylated trypsin and trypsin inhibitor were from New England Biolabs (Pickering, ON, Canada) and Sigma-Aldrich respectively. The ProteoExtract Albumin/IgG Removal kit was obtained from Calbiochem/EMD Millipore (Mississauga, ON, Canada). General laboratory chemicals were supplied by Sigma-Aldrich and Fisher Scientific.

\section{Cell culture}

Primary cultures of porcine coronary artery SMCs were generated from the left anterior descending coronary artery by an explant method, and quiescent cells were prepared as described previously (Saward \& Zahradka 1997b) by placement into serum-free supplemented medium for 5 days.
DNA synthesis assay

Quiescent cells were prepared in 24-well dishes and stimulated by direct addition of the indicated compounds without replacing the media. When inhibitors were used, they were added $60 \mathrm{~min}$ before addition of $0 \cdot 1 \mu \mathrm{g} / \mathrm{ml}$ PDGF. DNA synthesis was measured by incubating the cells with $1 \mu \mathrm{Ci}\left[{ }^{3} \mathrm{H}\right]$ thymidine, added $24 \mathrm{~h}$ after mitogen stimulation, for $48 \mathrm{~h}$ as described previously (Saward \& Zahradka 1997a).

\section{Protein synthesis assay}

Quiescent SMCs, prepared as described for the DNA synthesis assay, were placed into leucine-free media for $24 \mathrm{~h}$. The cells were subsequently treated with inhibitors (if applicable) for $60 \mathrm{~min}$ before stimulation with $0 \cdot 1 \mu \mathrm{g} / \mathrm{ml}$ PDGF. After $10 \mathrm{~min}, 10 \mu \mathrm{Ci}\left[{ }^{3} \mathrm{H}\right]$ leucine was added to each well. The cells were incubated for $5 \mathrm{~h}$, rinsed with PBS, and placed into $1 \mathrm{ml}$ cold 10\% trichloroacetic acid (TCA) for $15 \mathrm{~min}$. The cells were rinsed twice with cold 10\% TCA and subsequently lysed with $0.5 \mathrm{M} \mathrm{NaOH} / 0 \cdot 1 \%$ Triton X-100. The solution was transferred into scintillation vials containing EcoLume (GE Healthcare, Mississauga, ON, Canada) and the radioactivity quantified with a Beckman LS6500 Multi-Purpose Scintillation Counter.

\section{Protease digestion}

Adiponectin $(1 \mu \mathrm{g})$ was incubated with acetylated trypsin $(0 \cdot 2 \mu \mathrm{g})$ for $24 \mathrm{~h}$ at $37^{\circ} \mathrm{C}$ in $50 \mathrm{mM}$ Tris- $\mathrm{HCl} \mathrm{pH} 8 \cdot 0 / 20 \mathrm{mM}$ $\mathrm{CaCl}_{2}$ (total reaction volume $=20 \mu \mathrm{l}$ ). The reaction was terminated by addition of trypsin inhibitor $(0.85 \mu \mathrm{g})$. Appropriate amounts of the digestion product were used directly without further manipulation. Control reactions included i) adiponectin or globular adiponectin incubated in the absence of trypsin and ii) trypsin incubated without adiponectin.

\section{Western blotting}

Extracts prepared by direct addition of $150 \mu \mathrm{l} 2 \times \mathrm{SDS} /$ gel loading buffer to cells in 12-well culture dishes were loaded onto $7 \cdot 5 \%$ polyacrylamide gels after boiling for $2 \mathrm{~min}$ (Yau et al. 2003). Following electrophoresis, the proteins were transferred to PVDF membrane and probed with primary antibodies to eukaryotic elongation factor 2 kinase (eEF2K), phosphoeEF2K, phosphorylated extracellular-regulated kinase (ERK1/2), phospho-Akt, phospho-AMPK, phospho-IкB kinase (IKK), phospho-NF- $\mathrm{B}$ p65 (all from Cell Signaling, Pickering, ON, Canada), adiponectin (Calbiochem), and globular adiponectin (Phoenix). Band intensities were quantified as previously described (Yau et al. 2003). For western blotting of serum proteins from Sprague Dawley rats, abundant proteins were removed with the ProteoExtract Albumin/IgG Removal Kit before electrophoresis of $5 \mu \mathrm{g}$ protein. Antibodies tested on the rat serum included anti-adiponectin, C1Q, and collagen domain containing 
polyclonal antibody (Lifespan Biosciences, Seattle, WA, USA), anti-adiponectin/Acrp30 monoclonal antibody (R\&D Systems), and anti-gAcrp30/adipolean polyclonal antibody (Peprotech).

\section{Adiponectin oligomer formation}

Adiponectin $(1 \mu \mathrm{g})$ and globular adiponectin $(0 \cdot 5 \mu \mathrm{g})$ were mixed with $10 \mu \mathrm{l}$ buffer consisting of $62.5 \mathrm{mM}$ Tris- $\mathrm{HCl}$ $\mathrm{pH} 6.8$ and $20 \%$ glycerol and left at ambient temperature for $10 \mathrm{~min}$. Bromophenol blue was added to a final concentration of $0.005 \%$ and the samples were loaded onto a $5 \%$ polyacrylamide gel that lacked SDS. After the dye had reached the bottom of the gel, the proteins were visualized with Coomassie blue stain (Zahradka \& Ebisuzaki 1984) and images were captured with a digital camera.

\section{RT-PCR amplification}

RT-PCR was conducted as described previously (Noto et al. 2006) with $1 \mu \mathrm{g}$ total RNA isolated from SMCs with TRIzol (Invitrogen). Oligonucleotide primers for $\mathrm{GAPDH}$ (sense: 5'-CGGAGTG AACGGATTTGGCCGCAT-3', antisense: 5'-AGCCTTCTCCATGGTCGTGAAG-3'), AdipoR1 (sense: 5'-CTCTCCATCGTCTGTGTCCTGG-3', antisense: 5'-CCCATCTGGCCCACGGTGGTGG-3'), and AdipoR2 (sense: 5'-TGAAGGACAACGACTACCTGCT-3', antisense: 5'-CACCACCTTCTCCTGAAGGGGG-3') were designed based on Sus scrofa sequences available in Genbank (AF017079, NM_001007193, and NM_001007192 respectively).

\section{Statistical analysis}

All data are presented as mean \pm s.E.M. Student's $t$-tests were conducted among means of data to detect significant differences. Differences were accepted as significant at $P<0 \cdot 05$.

\section{Results}

Differential actions of adiponectin and globular adiponectin on SMC proliferation

DNA and protein synthesis were measured after treatment of quiescent SMCs with either $0 \cdot 1 \mu \mathrm{g} / \mathrm{ml}$ PDGF or $10 \mu \mathrm{g} / \mathrm{ml}$ adiponectin. Thymidine incorporation was increased over tenfold by both treatments (Fig. 1A). Leucine incorporation was likewise elevated (PDGF ninefold and adiponectin 1.5-fold) by both agents (Fig. 1B). No additive effects were obtained if cells were treated simultaneously with both PDGF and adiponectin (Fig. 1A and B). By contrast, addition of $2 \mu \mathrm{g} / \mathrm{ml}$ globular adiponectin had no effect on thymidine incorporation by quiescent SMCs (Fig. 1C). However, globular adiponectin reduced thymidine incorporation in response to PDGF by $90 \%$ (Fig. 1C). These data suggest that the anti-proliferative actions of adiponectin may be mediated by globular adiponectin.
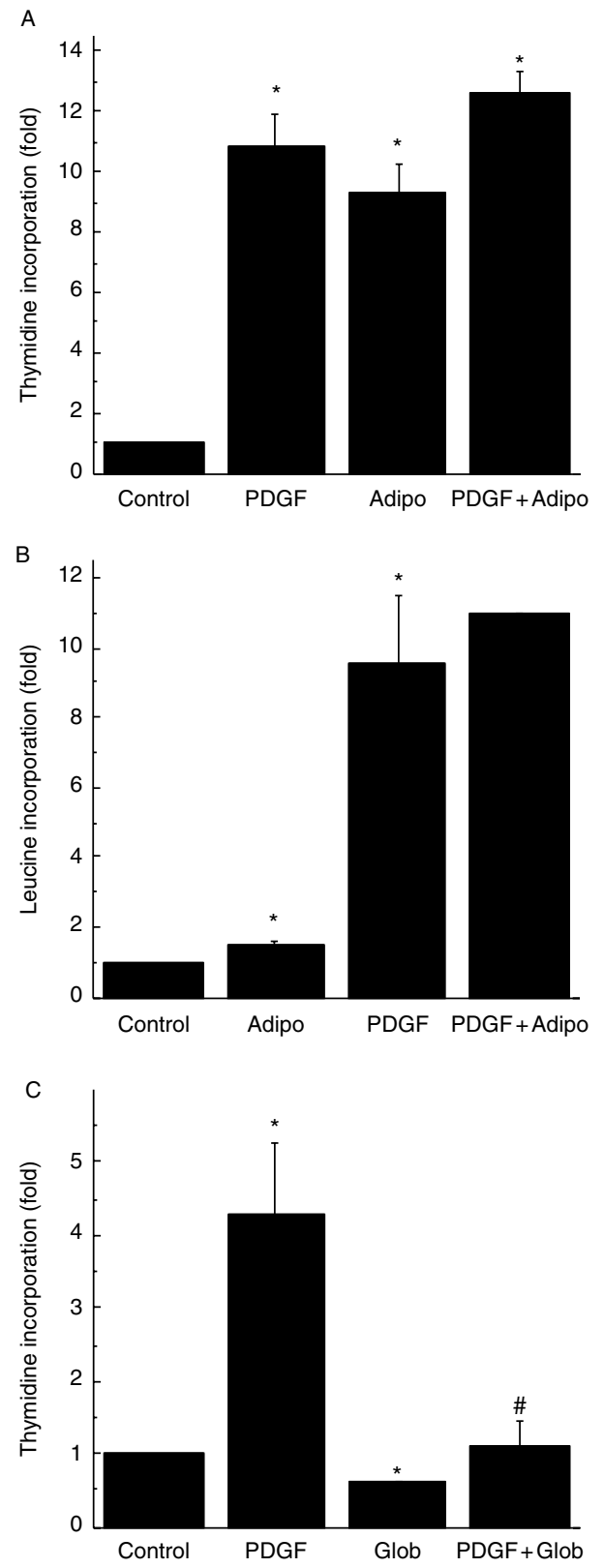

Figure 1 Smooth muscle cell proliferation in response to adiponectin and globular adiponectin. (A) Quiescent SMCs (control) were prepared in 24-well culture dishes and treated with $0 \cdot 1 \mu \mathrm{g} / \mathrm{ml} \mathrm{PDGF}$, $10 \mu \mathrm{g} / \mathrm{ml}$ adiponectin (Adipo), or a combination of both agents. DNA synthesis was measured by incorporation of $\left[{ }^{3} \mathrm{H}\right]$ thymidine. The radiolabel was added $24 \mathrm{~h}$ after treatment, and cells were harvested for measurement $48 \mathrm{~h}$ later. (B) Protein synthesis in response to PDGF and adiponectin was measured by leucine incorporation. Treatment conditions were identical to those of panel A. Radiolabel was added immediately after treatments and cells were harvested after 5 h. (C) Quiescent cells (control) were treated with $0 \cdot 1 \mu \mathrm{g} / \mathrm{ml}$ PDGF, $2 \mu \mathrm{g} / \mathrm{ml}$ globular adiponectin (Glob), or a combination of both agents and DNA synthesis was measured as described in panel A. The data are presented as mean \pm S.E.M. for $n=3$, with the control value set to 1 . *Significant at $P<0.05$ from control; ${ }^{*}$ significant at $P<0 \cdot 05$ from PDGF treatment (panel $C$ only). 
Adiponectin and globular adiponectin activate different intracellular signaling pathways

Quiescent SMCs were treated with $10 \mu \mathrm{g} / \mathrm{ml}$ adiponectin for $10 \mathrm{~min}$ and the cells were subsequently harvested for western blot analysis. Increased phosphorylation of the

A
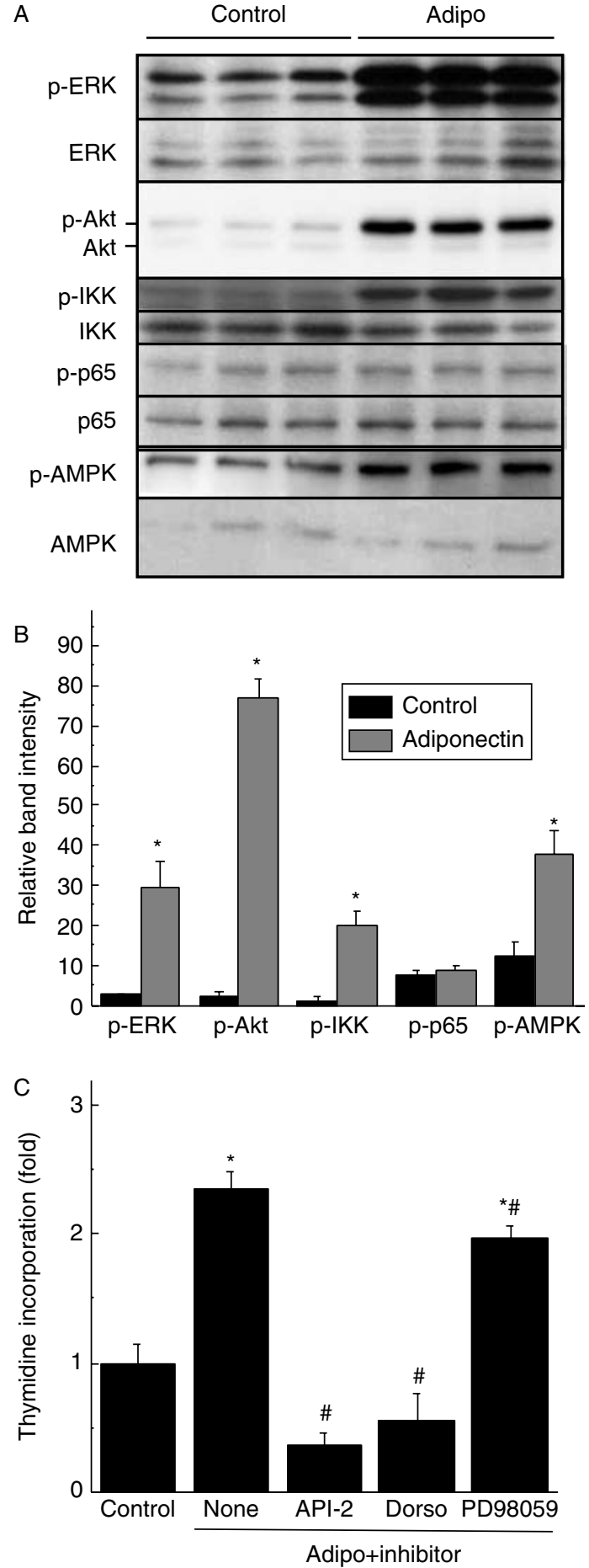

Journal of Endocrinology (2012) 215, 107-117 proliferation-associated kinases ERK1/2, Akt, and IKK were observed (Fig. 2A and B). Interestingly, phosphorylation

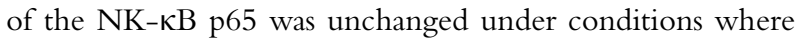
phosphorylation of IKK was increased. As reported previously (Yamauchi et al. 2002), adiponectin stimulated phosphorylation of AMPK.

To investigate the contribution of these signaling pathways to the mitogenic actions of adiponectin, we examined cell proliferation in response to adiponectin in the presence of inhibitors of ERK1/2 (PD98059), Akt (API-2), and AMPK (dorsomorphin). As was seen in Fig. 1, treatment of quiescent SMCs with $10 \mu \mathrm{g} / \mathrm{ml}$ adiponectin significantly increased thymidine incorporation; however, both API-2 and dorsomorphin blocked the actions of adiponectin (Fig. 2C). These data suggest that both Akt and AMPK are required for SMC proliferation in response to adiponectin, while ERK1/2 is not.

Treatment of SMCs with a mitogen, $0 \cdot 1 \mu \mathrm{g} / \mathrm{ml}$ PDGF, increased the phosphorylation of ERK1/2 and Akt (Fig. 3). PDGF treatment also elevated phosphorylation of eEF2K, a mediator of protein synthesis. While no change in the phosphorylation state of ERK1/2 or Akt was detected after addition of $2 \mu \mathrm{g} / \mathrm{ml}$ globular adiponectin, it was observed that PDGF-dependent eEF2K phosphorylation was blocked in the presence of globular adiponectin (Fig. 3). By contrast, addition of adiponectin in conjunction with PDGF had no additional effects beyond those seen with PDGF alone (data not shown), which concur with the results previously seen with DNA and protein synthesis (Fig. 1A and B).

\section{Activation of AMPK does not inhibit DNA synthesis}

Phosphorylation of AMPK in response to adiponectin (Fig. 2), aminoimidazole carboxamide ribonucleotide (AICAR; Fig. 4A), a known activator of AMPK (Corton et al. 1995), and globular adiponectin (Fig. 4A) was expected based on published data. By contrast, AMPK phosphorylation in cells treated with PDGF was not anticipated (Fig. 4A).

Figure 2 Stimulation of intracellular signaling by adiponectin. Quiescent SMCs (control) were treated with $2 \mu \mathrm{g} / \mathrm{ml}$ adiponectin (Adipo) for $15 \mathrm{~min}$. Cell extracts were subsequently analyzed by western blotting for phosphorylation of ERK1/2, Akt, IKK, NF-KB p65, and AMPK. GAPDH was used as the loading control. Panel A shows a representative blot (repeated three times) with triplicate samples from one experiment. (B) The band intensity of the phosphorylated protein was quantified by scanning densitometry and plotted relative to the intensity of the unphosphorylated protein (B). The data are presented as mean \pm s.E.M., with the lowest value set to 1 . *Significant at $P<0 \cdot 05$ from control. (C) Quiescent cells (control) were treated with $10 \mu \mathrm{g} / \mathrm{ml}$ Adipo in the absence (none) or presence of various inhibitors $(0 \cdot 1 \mu \mathrm{M} \mathrm{API}-2,1 \mu \mathrm{M}$ dorsomorphin (DORSO), and $10 \mu \mathrm{M}$ PD98059). Inhibitors were added 15 min before stimulation with adiponectin. DNA synthesis was measured as described in Fig. 1. The data are presented as mean \pm S.E.M. for $n=3$, with the control value set to 1 . *Significant at $P<0.05$ from control; ${ }^{*}$ significant at $P<0.05$ from adiponectin treatment with no inhibitors. 

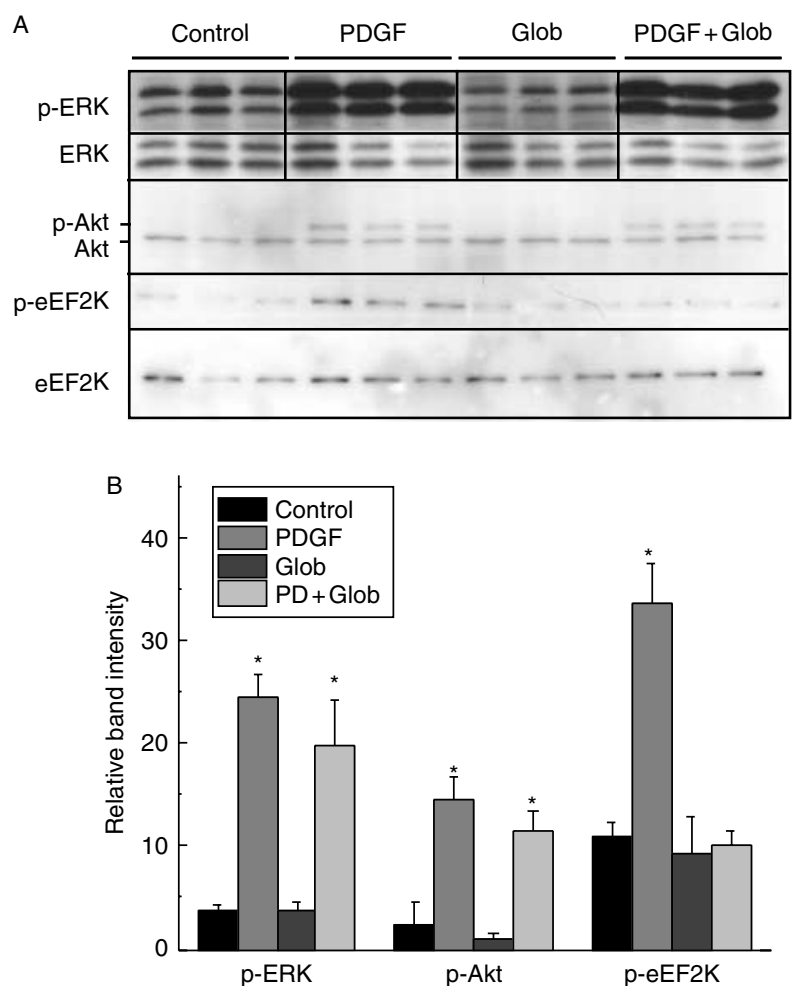

Figure 3 Effect of PDGF and globular adiponectin on intracellular signaling intermediates. Quiescent SMCs (control) were prepared in 24-well culture dishes and treated with $0 \cdot 1 \mu \mathrm{g} / \mathrm{ml} \mathrm{PDGF,}$ $10 \mu \mathrm{g} / \mathrm{ml}$ globular adiponectin (Glob), or a combination of both agents for $15 \mathrm{~min}$. Cell extracts were subsequently analyzed by western blotting for phosphorylation of eEF2K, ERK1/2, Akt, and IKK. Equivalent sample loading was verified with non-phosphorylated eEF2K. Panel A shows triplicate samples from experiments that were replicated three times. Vertical lines separate groups that were taken from the same gel but rearranged to match the headings. In panel B, the band intensities of each phosphorylated protein relative to the respective unphosphorylated protein are presented as mean \pm s.E.M., with the lowest value set to 1 . *Significant at $P<0.05$ from control.

AMPK activation has been reported to block DNA synthesis (Igata et al. 2005), a response that is inconsistent with the actions of a potent mitogen-like PDGF (Fig. 1A). Also, these results do not agree with the growth stimulatory actions of adiponectin (Fig. 1A). Consequently, the presence of phosphorylated AMPK in mitogen-treated cells suggests that AMPK does not inhibit cell proliferation. To confirm this interpretation, we compared the actions of adiponectin and AICAR on PDGF-stimulated thymidine incorporation. Treatment with PDGF increased DNA synthesis by quiescent SMCs almost 2.5-fold (Fig. 4B). The presence of adiponectin did not significantly interfere with the stimulation elicited by PDGF. Finally, AICAR was unable to block the increase in thymidine incorporation elicited by PDGF. Confirmation that AICAR specifically targets AMPK is reported elsewhere (Mohankumar et al. 2012). These results indicate that activation of AMPK by adiponectin and globular adiponectin is not an indication of an anti-proliferative activity. To determine whether AMPK was required for proliferation in response to PDGF, quiescent SMCs were treated with PDGF in the presence of the AMPK inhibitor dorsomorphin. Under these conditions, induction of thymidine incorporation by PDGF was reduced to below basal levels (Fig. 4C), although there was no change in cell number or appearance (data not shown). Also, as dorsomorphin has been shown to affect SMAD activation (Yu et al. 2008), we examined whether PDGF stimulates SMAD phosphorylation. The finding that SMAD activation does not occur with PDGF treatment (data not shown) confirms that the effects of dorsomorphin seen in this study are mediated via AMPK. These results thus indicate that activation of AMPK appears to be a requisite for SMC proliferation following stimulation with a mitogen.

The AdipoR1 receptor mediates AMPK activation by adiponectin (Kadowaki \& Yamauchi 2005). We therefore employed RT-PCR to determine whether this receptor was expressed by the SMCs used in these experiments. As shown in Fig. 4D, amplification products specific for both AdipoR1 and AdipoR2 were detectable. These data establish that AMPK activation via AdipoR1 is a reasonable expectation.

\section{Tryptic cleavage of adiponectin alters its ability to stimulate cell proliferation}

The adiponectin and globular adiponectin employed in our study had molecular masses of 30 and $18 \mathrm{kDa}$ (Fig. 5A), which agree with the values for the native proteins (Fruebis et al. 2001). Furthermore, both proteins are capable of forming oligomeric complexes of two to six polypeptides (Fig. 5B), as previously reported (Tsao et al. 2002). Although the enzyme responsible for cleavage of adiponectin has not been identified, both trypsin and leukocyte elastase have been shown to generate in vitro a truncated form of adiponectin that consists of the globular domain (Fruebis et al. 2001, Waki et al. 2005). This protein fragment not only has a molecular mass similar to globular adiponectin, but also exhibits the biological activity associated with this protein (Fruebis et al. 2001, Waki et al. 2005). Consequently, we elected to use trypsin digestion to determine the functional relationship between the intact adiponectin and the truncated globular form.

Conditions appropriate for trypsin digestion of adiponectin were identified, and western blotting showed that the primary product was a polypeptide of $\sim 18 \mathrm{kDa}$. Although some undigested $30 \mathrm{kDa}$ adiponectin remained, as well as an intermediate $25 \mathrm{kDa}$ form, more than $90 \%$ of the input was cleaved. Not only did the product co-migrate with globular adiponectin, it was also recognized immunologically as globular adiponectin (Fig. 5C). To assess the effect of cleavage on adiponectin's biological activity, thymidine incorporation was monitored in quiescent SMCs treated with adiponectin and the product of adiponectin cleaved with trypsin (Fig. 5D). 
It was observed that the increased DNA synthesis obtained with adiponectin was significantly reduced following cleavage of adiponectin with trypsin. The effect of trypsin and trypsin inhibitor, the latter being used to terminate the reaction,
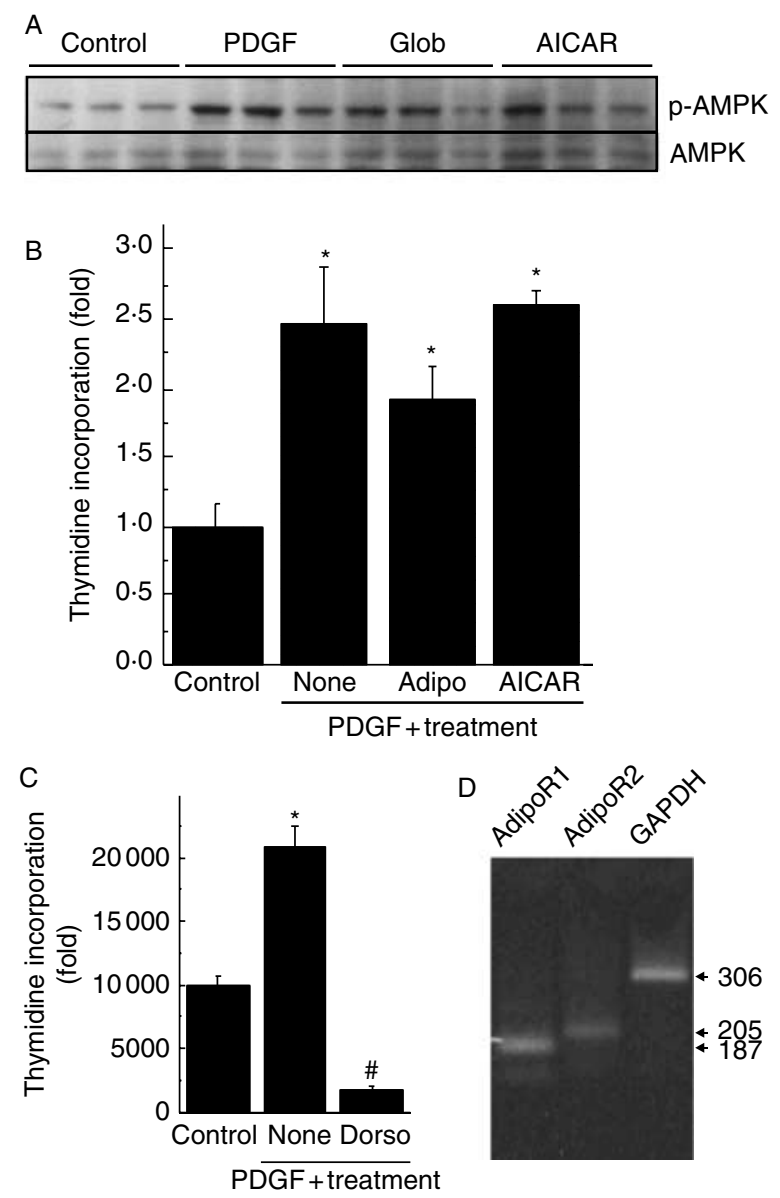

Figure 4 Modulation of AMPK phosphorylation state by PDGF, adiponectin, and globular adiponectin. (A) Phosphorylation of AMPK in response to treatment with $0 \cdot 1 \mu \mathrm{g} / \mathrm{ml}$ PDGF, $10 \mu \mathrm{g} / \mathrm{ml}$ globular adiponectin (Glob), and $10 \mathrm{mM}$ AICAR (positive control) for $15 \mathrm{~min}$ was measured by western blotting. The representative blot shows triplicate samples from one experiment; the experiment was replicated three times. GAPDH was used as the loading control. (B) Thymidine incorporation by PDGF-treated SMCs was measured in the presence of either $10 \mu \mathrm{g} / \mathrm{ml}$ adiponectin (Adipo) or $10 \mu \mathrm{M}$ AICAR according to the standard protocol described in Materials and Methods section. The data are presented as mean \pm S.E.M. for $n=3$, with the value for the control set to 1 . *Significantly different at $P<0 \cdot 05$ relative to untreated control. (C) Thymidine incorporation by SMCs stimulated with $0 \cdot 1 \mu \mathrm{g} / \mathrm{ml}$ PDGF, in the absence or presence of $1 \mu \mathrm{M}$ dorsomorphin (Dorso) as described for panel B. The data are presented as mean \pm s.E.M. for $n=3$, with the value for the control set to 1 . *Significantly different at $P<0.05$ relative to untreated control. " Significantly different at $P<0.05$ relative to PDGF-treated cells. (D) Total RNA extracted from quiescent SMCs was amplified with primers specific for the adiponectin receptors AdipoR1 and AdipoR2 or for the housekeeping gene Gapdh. The figure shows the positions of the amplified bands after agarose gel electrophoresis. was determined in a complete reaction (adiponectin + trypsin) to which trypsin inhibitor was added before commencing the incubation (digestion control). Inhibition of trypsin activity prevented the decrease in DNA synthesis that was obtained with the cleaved adiponectin. Of note, the reduced activity of digested adiponectin was not significantly different from that obtained with globular adiponectin. These results suggest that conversion of adiponectin to globular adiponectin alters its ability to affect SMC proliferation.

\section{Globular adiponectin is present in rat serum}

Although numerous studies have shown that globular adiponectin is biologically active, as we have in this investigation, whether this protein fragment exists in the circulation remains contentious. To address this issue, we used western blotting to determine whether globular adiponectin could be detected in rat serum, which was used because the antibodies tested were raised against rat protein. The native $30 \mathrm{kDa}$ protein was detected by three different antibodies (Fig. 6A), although a strong signal was only obtained with an antibody from R\&D Systems. Depleting the serum of the most abundant proteins (albumins and immunoglobulins) improved the quality of the signal with the antibody from R\&D Systems (Fig. 6B), but the signal was reduced with the other antibodies. Likewise, these antibodies detected a band at $18 \mathrm{kDa}$, the expected position of globular adiponectin, although it was faint with all but the R\&D Systems antibody (Fig. 6A and B). On the other hand, the antibody from R\&D Systems did not recognize either recombinant adiponectin or recombinant globular adiponectin, although recombinant adiponectin was visible with the antibody from Peprotech (Fig. 6C and D). Based on these results, we conclude that globular adiponectin is present in the circulation; however, the ability to detect its presence is dependent on the properties of the antibody being employed to distinguish between the native or recombinant proteins.

\section{Discussion}

The anti-atherogenic properties attributed to adiponectin and globular adiponectin are presumed to involve, at least in part, the ability to block SMC proliferation. While the direct effects of adiponectin on SMCs have been examined (Wang et al. 2005), a similar investigation of globular adiponectin has yet to be reported. We therefore undertook to compare the actions of adiponectin and globular adiponectin on SMC proliferation, using DNA and protein synthesis as surrogates for this process (Louis et al. 2011). In contrast to expectations, our results revealed that adiponectin stimulates SMC proliferation while globular adiponectin blocks the actions of PDGF, a potent SMC mitogen (Fig. 1). These observations were supported by evidence that adiponectin triggers signaling cascades typically associated with cell proliferation, including ERK1/2 and Akt, which also respond to PDGF, 
A

B

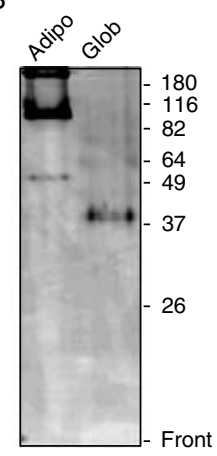

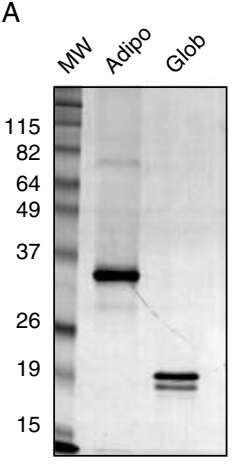
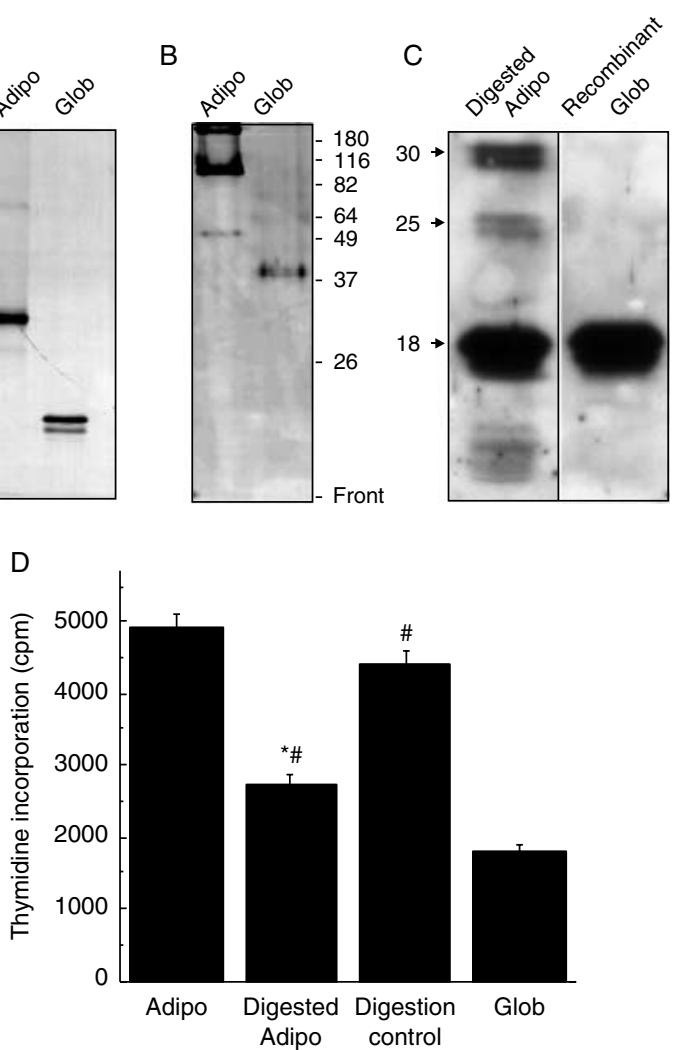

Figure 5 Effect of protease digestion on activity of adiponectin. (A) Adiponectin (Adipo) and globular adiponectin (Glob) are shown by Coomassie blue staining after SDS-PAGE. The position of the molecular mass markers run in parallel is indicated. (B) Oligomer formation by adiponectin (Adipo) and globular adiponectin (Glob) was monitored by non-denaturing PAGE as described in Materials and Methods section. The position of the molecular mass markers run in parallel is indicated. (C) SDS-PAGE of adiponectin digested with trypsin (Digested Adipo) as described in Materials and Methods section. Globular adiponectin (Glob) was loaded on the adjacent lane for comparison. The bands were detected by western blotting with a globular adiponectin-specific antibody (Peprotech). (D) Thymidine incorporation was measured after addition of $1 \mu \mathrm{g}$ adiponectin (Adipo), $1 \mu \mathrm{g}$ digested adiponectin (Digested Adipo), and $0.5 \mu \mathrm{g}$ globular adiponectin (Glob) to quiescent SMCs stimulated with $0 \cdot 1 \mu \mathrm{g} / \mathrm{ml}$ PDGF. The digested adiponectin was prepared as described in Materials and Methods section. Both adiponectin and globular adiponectin were mixed with the digestion buffer before their addition. The digestion control included trypsin inhibitor with trypsin and adiponectin during the incubation period. The raw data in c.p.m. are presented as mean \pm S.E.M. for $n=3$. *Significantly different at $P<0 \cdot 05$ relative to adiponectin (Adipo) treatment; ${ }^{*}$ significantly different at $P<0 \cdot 05$ relative to globular adiponectin (Glob) treatment.

and that inhibitors of these signal transduction pathways block the proliferative response (Fig. 2). By contrast, globular adiponectin interfered with activation of eEF2K by PDGF. As AMPK was phosphorylated in response to adiponectin, PDGF, and globular adiponectin (Fig. 4), it was difficult to conclude that AMPK was associated with SMC proliferation. However, the observation that inhibition of AMPK blocks the mitogenic actions of PDGF and adiponectin (Figs 2C and $4 \mathrm{C}$ ) indicates that AMPK activation is necessary for cell proliferation. Finally, proteolytic conversion of adiponectin to globular adiponectin, which we show is detectable in normal rat serum, altered the ability of this molecule to stimulate SMC proliferation (Fig. 5), thus confirming that adiponectin and globular adiponectin had opposite effects on this process.

An increase in nitric oxide (NO) production by vascular endothelial cells (Chen et al. 2003) is one mechanism that has been proposed to explain the inverse relationship between serum adiponectin levels and the elevated incidence of vascular disease in diabetes, metabolic syndrome, atherosclerosis, and hypertension (Giannessi et al. 2007, Hung et al. 2008). NO is a potent anti-atherogenic agent as atherosclerosis is prevalent in mice that lack NO synthase (NOS; Knowles et al. 2000) and NO inhibits SMC proliferation (Sato et al. 2000). Chen et al. (2003) reported that adiponectin increases endothelial NOS (eNOS) activity in endothelial cells through AMPK-dependent phosphorylation. Globular adiponectin likewise was shown to increase eNOS activity and additionally stimulate eNOS expression (Hattori et al. 2003). Both forms of adiponectin can thus influence vasodilation (Schmid et al. 2011).

Direct inhibition of vascular SMC proliferation could also explain the anti-atherosclerotic actions of adiponectin (Zhu et al. 2008), although promoting differentiation to the quiescent phenotype would have a similar effect (Ding et al. 2011). Adiponectin has been reported to inhibit SMC proliferation in response to a variety of different growth-promoting agents (Matsuda et al. 2002), possibly by sequestering growth factors (Wang et al. 2005). Matsuda et al. (2002) also reported that adiponectin reduced neointimal hyperplasia in response to arterial injury (restenosis), a process that is closely associated
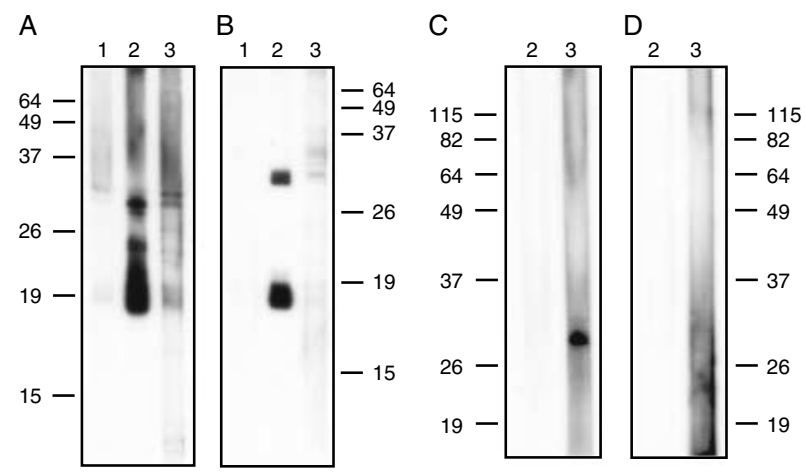

Figure 6 Antibody-dependent detection of globular adiponectin. Western blotting was used to compare various commercial antibodies for their ability to detect native and recombinant forms of adiponectin and globular adiponectin. Rat serum was tested (A) before or (B) after depletion of abundant proteins with antibodies from Lifespan Biosciences (1), R\&D Systems (2), and Peprotech (3). Antibodies 2 and 3 were also tested with $50 \mathrm{ng}$ of adiponectin (C) and globular adiponectin (D). Molecular mass markers were run in parallel on each gel. The results were replicated three times. 
with SMC proliferation. The latter observation is supported by several studies that have linked restenosis with low circulating adiponectin levels (Kubota et al. 2002, Nishimura et al. 2006, Kitta et al. 2008). However, these investigations have neither tested the effect of globular adiponectin in their systems nor verified the physical characteristics of the protein. In contrast to these observations, however, Lee et al. (2008) reported that treatment of SMCs with adiponectin resulted in ERK1/2 activation. Furthermore, these investigators showed a similar response occurred in endothelial and HEK293 cells and that adiponectin stimulated the proliferation of HEK293 cells (Lee et al. 2008).

With respect to other cell types, there is no consistency regarding the effect of adiponectin on growth. For instance, adiponectin has been reported to inhibit the proliferation of hepatic stellate and breast cancer cells (Adachi \& Brenner 2008, Nakayama et al. 2008) and promote the proliferation of epithelial, breast, and prostate cancer cells, as well as osteoblasts and hematopoietic stem cells (Luo et al. 2006, Ogunwobi \& Beales 2006, DiMascio et al. 2007, Mistry et al. 2008, Pfeiler et al. 2008). Additionally, adiponectin had no effect on the proliferation of normal and transformed breast cancer cells and adenocarcinomas (Grossmann et al. 2008, Ogunwobi \& Beales 2008). Similar results have been obtained with globular adiponectin, with i) growth of epithelial cancer cells, fibroblasts, and hematopoietic stem cells increased (Ogunwobi \& Beales 2006, DiMascio et al. 2007, Hattori et al. 2007); ii) epithelial and breast cancer cells and adenocarcinomas growth inhibited (Fenton et al. 2008, Grossmann et al. 2008, Ogunwobi \& Beales 2008); and iii) growth of normal breast cells and prostate cancer cells unaffected (Grossmann et al. 2008, Mistry et al. 2008). In studies that directly compared the two forms of adiponectin, both different (breast, prostate, and adenocarcinoma) and similar (epithelial and stem cells) responses have been observed.

Are these varied results due to the different oligomeric structures formed by adiponectin and globular adiponectin, or are they due to the presence of different receptors on the cells? The issue of oligomers is an important one given the fact these exist in vivo (Schraw et al. 2008) and have been shown to affect the differentiation state of SMCs (Ding et al. 2011). As part of this investigation, we established that fulllength adiponectin formed dimers, trimers, and structures $>180 \mathrm{kDa}$ (likely hexamers) according to analysis with nondenaturing gel electrophoresis (Fig. 5B). These data resemble those reported by Palanivel et al. (2007) who found recombinant adiponectin produced with a mammalian expression system likewise preferentially formed high and medium size oligomers. By contrast, globular adiponectin predominantly formed dimers, with only small amounts of trimers and possibly tetramers visible. The adiponectin receptors exhibit different affinities for adiponectin and globular adiponectin (Yamauchi et al. 2003a,b). Specifically, it has been shown that globular adiponectin binds to both AdipoR1 and AdipoR2, while adiponectin binds more favorably to AdipoR2. However, as the porcine coronary artery SMCs employed in this investigation express both adiponectin receptors (Fig. 5E), and both adiponectin forms elicited a biological response (Figs 1, 2 and 3), the different results seen with adiponectin and globular adiponectin are most likely not a consequence of differences in the receptors.

As AMPK phosphorylation has been linked to inhibition of SMC proliferation (Nagata et al. 2004, Igata et al. 2005), activation of AMPK would not be expected if adiponectin and globular adiponectin stimulate SMC proliferation. On the other hand, AMPK phosphorylation occurred upon treatment with PDGF, a potent mitogen (Figs 2 and 3), which suggests that AMPK activation may not be strictly associated with growth inhibition. Although these data do not agree with the concept that AMPK has anti-proliferative activity (Motoshima et al. 2006), two recent reports have shown that AMPK promotes the proliferation of osteoblastic cells and fibroblasts (Hattori et al. 2006, Kanazawa et al. 2008). In agreement with these findings, inhibition of AMPK blocked SMC proliferation in response to both PDGF and adiponectin, which thus implies that AMPK likely has a role in SMC proliferation. Regardless, the fact that AMPK becomes phosphorylated in SMCs treated with adiponectin and globular adiponectin suggests that this protein is required for signal transduction from AdipoR1, which both proteins stimulate, whether proliferation occurs or not. It is worth noting, however, that $\mathrm{T}$ cadherin has also been shown to mediate activation of AMPK in response to adiponectin (Denzel et al. 2010), and this protein is highly abundant in SMCs (Takeuchi et al. 2007).

Although numerous studies have examined the effects of globular adiponectin on cells and animals, the physiological relevance of this protein remains unresolved. We were able to detect globular adiponectin in rat serum with three different antibodies, with only the monoclonal antibody providing a strong signal (Fig. 6) and only with the native protein. Fruebis et al. (2001) were the first to propose that proteolytic cleavage was a factor in the regulation of adiponectin's biological function. Consequently, our demonstration that globular adiponectin can be detected in serum samples (albeit this is antibody dependent) may be considered validation of this premise. Furthermore, many different studies using globular adiponectin have been published. As described earlier, there are many examples where responses to globular adiponectin were similar to those obtained with full-length adiponectin. However, there are equally as many reports showing that cells exhibit quite distinct responses to these different forms of adiponectin. This investigation has attempted to bridge the gap by comparing the response of one cell type to both forms of adiponectin. Even so, there is essentially no information about globular adiponectin in vivo. The limitation for studying globular adiponectin may be attributable to a lack of resources for detection and quantification of this polypeptide. Few antibodies capable of binding globular adiponectin are available, and an ELISA that is specific for globular adiponectin does not exist. Indeed, our data suggest that the 
ability to bind native vs recombinant adiponectin or globular adiponectin may also be a factor. Thus, while there is still controversy regarding the presence of globular adiponectin in human serum, it is also true that very few attempts have been made to search for it. A recent report, however, provides some intriguing information regarding the possible target for globular adiponectin. Specifically, Almer et al. (2011) have shown that fluorescently tagged globular adiponectin accumulates in the fibrous cap region of atherosclerotic lesions. Although these results do not provide information about the production, circulating levels, or function of globular adiponectin in vivo, they do strongly support the existence of a relationship between this protein and atherosclerotic disease.

It is now evident that the complement $\mathrm{C} 1 \mathrm{q}$ region of adiponectin is capable of binding to the adiponectin receptors when separated from the rest of the adiponectin molecule (Yamauchi et al. 2003a,b). Whether it exists as a separate biologically active 'globular adiponectin' remains to be determined. Nevertheless, proteolytic cleavage of polypeptide hormones is an accepted mechanism of regulating activity. Both Fruebis et al. (2001) and Waki et al. (2005) have shown that proteolytic cleavage of adiponectin in vitro with either trypsin or leukocyte elastase respectively generates a proteolytic fragment that physically and pharmacologically resembles the globular adiponectin molecule found in human serum. While Waki et al. (2005) argue that leukocyte elastase is the serum factor that is responsible for globular adiponectin formation in vivo, it remains to be seen whether this is the case. Further study will therefore be required to establish whether globular adiponectin is biologically active at the concentration found in serum and to determine the physiological relevance of adiponectin cleavage with respect to vascular disease. Nevertheless, these results establish that globular adiponectin is a naturally occurring protein and further investigation of its physiological function in vivo is warranted.

\section{Declaration of interest}

The authors declare that there is no conflict of interest that could be perceived as prejudicing the impartiality of the research reported.

\section{Funding}

Funding for this research was generously provided by the Canadian Institutes for Health Research (to P Z) and the Natural Sciences and Engineering Research Council of Canada (to C G T). M F was a recipient of an NSERC Canada Graduate scholarship.

\section{Acknowledgements}

The authors would like to thank Natalia Yurkova and Raissa Perrault for technical assistance and Vanessa DeClercq for providing rat serum. They would also like to acknowledge the St Boniface Hospital and Research Foundation for infrastructure support.

\section{References}

Adachi M \& Brenner DA 2008 High molecular weight adiponectin inhibits proliferation of hepatic stellate cells via activation of adenosine monophosphate-activated protein kinase. Hepatology 47 677-685. (doi:10.1002/hep.21991)

Almer G, Saba-Lepek M, Haj-Yahya S, Rohde E, Strunk D, Frohlich E, Prassl R \& Mangge H 2011 Globular domain of adiponectin: promising target molecule for detection of atherosclerotic lesions. Biologics 5 95-105. (doi:10.2147/BTT.S22863)

Chen H, Montagnani M, Funahashi T, Shimomura I \& Quon MJ 2003 Adiponectin stimulates production of nitric oxide in vascular endothelial cells. Journal of Biological Chemistry 278 45021-45026. (doi:10.1074/jbc. M307878200)

Clasen R, Schupp M, Foryst-Ludwig A, Sprang C, Clemenz M, Krikov M, Thone-Reineke C, Unger T \& Kintscher U 2005 PPAR $\gamma$-activating angiotensin type-1 receptor blockers induce adiponectin. Hypertension $\mathbf{4 6}$ 137-143. (doi:10.1161/01.HYP.0000168046.19884.6a)

Corton JM, Gillespie JG, Hawley SA \& Hardie DG 1995 5-Aminoimidazole4-carboxamide ribonucleoside. A specific method for activating AMP-activated protein kinase in intact cells? European Journal of Biochemistry 229 558-565. (doi:10.1111/j.1432-1033.1995.tb20498.x)

DeClercq V, Taylor C \& Zahradka P 2008 Adipose tissue: the link between obesity and cardiovascular disease. Cardiovascular \& Hematological Disorders Drug Targets 8 228-237. (doi:10.2174/187152908785849080)

Denzel MS, Scimia MC, Zumstein PM, Walsh K, Ruiz-Lozano P \& Ranscht B 2010 T-cadherin is critical for adiponectin-mediated cardioprotection in mice. Journal of Clinical Investigation 120 4342-4352. (doi:10.1172/JCI43464)

DiMascio L, Voermans C, Uqoezwa M, Duncan A, Lu D, Wu J, Sankar U \& Reya T 2007 Identification of adiponectin as a novel hemopoietic stem cell growth factor. Journal of Immunology 178 3511-3520.

Ding M, Xie Y, Wagner RJ, Jin Y, Carrao AC, Liu LS, Guzman AK, Powell RJ, Hwa J, Rzucidlo EM et al. 2011 Adiponectin induces vascular smooth muscle cell differentiation via repression of mammalian target of rapamycin complex 1 and FoxO4. Arteriosclerosis, Thrombosis, and Vascular Biology 31 1403-1410. (doi:10.1161/ATVBAHA.110.216804)

Do D, Alvarez J, Chiquette E \& Chilton R 2006 The good fat hormone: adiponectin and cardiovascular disease. Current Atherosclerosis Reports $\mathbf{8}$ 94-99. (doi:10.1007/s11883-006-0045-5)

Fenton JI, Birmingham JM, Hursting SD \& Hord NG 2008 Adiponectin blocks multiple signaling cascades associated with leptin-induced cell proliferation in Apc Min/ + colon epithelial cells. International Journal of Cancer 122 2437-2445. (doi:10.1002/ijc.23436)

Fruebis J, Tsao TS, Javorschi S, Ebbets-Reed D, Erickson MR, Yen FT, Bihain BE \& Lodish HF 2001 Proteolytic cleavage product of 30-kDa adipocyte complement-related protein increases fatty acid oxidation in muscle and causes weight loss in mice. PNAS 98 2005-2010. (doi:10.1073/pnas.041591798)

Giannessi D, Maltinti M \& Del Ry S 2007 Adiponectin circulating levels: a new emerging biomarker of cardiovascular risk. Pharmacological Research 56 459-467. (doi:10.1016/j.phrs.2007.09.014)

Grossmann ME, Nkhata KJ, Mizuno NK, Ray A \& Cleary MP 2008 Effects of adiponectin on breast cancer cell growth and signaling. British Journal of Cancer 98 370-379. (doi:10.1038/sj.bjc.6604166)

Hattori Y, Suzuki M, Hattori S \& Kasai K 2003 Globular adiponectin upregulates nitric oxide production in vascular endothelial cells. Diabetologia 46 1543-1549. (doi:10.1007/s00125-003-1224-3)

Hattori Y, Akimoto K, Nishikimi T, Matsuoka H \& Kasai K 2006 Activation of AMP-activated protein kinase enhances angiotensin II-induced proliferation in cardiac fibroblasts. Hypertension 47 265-270. (doi:10.1161/01.HYP.0000198425.21604.aa)

Hattori Y, Hattori S, Akimoto K, Nishikimi T, Suzuki K, Matsuoka H \& Kasai K 2007 Globular adiponectin activates nuclear factor-kappaB and activating protein- 1 and enhances angiotensin II-induced proliferation in cardiac fibroblasts. Diabetes 56 804-808. (doi:10.2337/ db06-1405) 
Hung J, McQuillan BM, Thompson PL \& Beilby JP 2008 Circulating adiponectin levels associate with inflammatory markers, insulin resistance and metabolic syndrome independent of obesity. International Journal of Obesity 32 772-779. (doi:10.1038/sj.ijo.0803793)

Igata M, Motoshima H, Tsuruzoe K, Kojima K, Matsumura T, Kondo T, Taguchi T, Nakamaru K, Yano M, Kukidome D et al. 2005 Adenosine monophosphate-activated protein kinase suppresses vascular smooth muscle cell proliferation through the inhibition of cell cycle progression. Circulation Research 97 837-844. (doi:10.1161/01.RES.0000185823.73556.06)

Kadowaki T \& Yamauchi T 2005 Adiponectin and adiponectin receptors. Endocrine Reviews 26 439-451. (doi:10.1210/er.2005-0005)

Kanazawa I, Yamaguchi T, Yano S, Yamauchi M \& Sugimoto T 2008 Metformin enhances the differentiation and mineralization of osteoblastic MC3T3-E1 cells via AMP kinase activation as well as eNOS and BMP-2 expression. Biochemical and Biophysical Research Communications 375 414-419. (doi:10.1016/j.bbrc.2008.08.034)

Kitta Y, Takano H, Nakamura T, Kodama Y, Umetani K, Fujioka D, Saito Y, Kawabata K, Obata JE, Mende A et al. 2008 Low adiponectin levels predict late in-stent restenosis after bare metal stenting in native coronary arteries. International Journal of Cardiology 131 78-82. (doi:10.1016/ j.jjcard.2007.09.004)

Knowles JW, Reddick RL, Jennette JC, Shesely EG, Smithies O \& Maeda N 2000 Enhanced atherosclerosis and kidney dysfunction in eNOS $(-/-)$ Apoe $(-/-)$ mice are ameliorated by enalapril treatment. Journal of Clinical Investigation 105 451-458. (doi:10.1172/JCI8376)

Kubota N, Terauchi Y, Yamauchi T, Kubota T, Moroi M, Matsui J, Eto K, Yamashita T, Kamon J, Satoh H et al. 2002 Disruption of adiponectin causes insulin resistance and neointimal formation. Journal of Biological Chemistry 277 25863-25866. (doi:10.1074/jbc.C200251200)

Lam KS \& Xu A 2005 Adiponectin: protection of the endothelium. Current Diabetes Reports 5 254-259. (doi:10.1007/s11892-005-0019-y)

Lee MH, Klein RL, El-Shewy HM, Luttrell DK \& Luttrell LM 2008 The adiponectin receptors AdipoR1 and AdipoR2 activate ERK1/2 through a Src/Ras-dependent pathway and stimulate cell growth. Biochemistry 47 11682-11692. (doi:10.1021/bi801451f)

Li CJ, Sun HW, Zhu FL, Chen L, Rong YY, Zhang Y \& Zhang M 2007 Local adiponectin treatment reduces atherosclerotic plaque size in rabbits. Journal of Endocrinology 193 137-145. (doi:10.1677/JOE-06-0173)

Louis S, Saward L \& Zahradka P 2011 Both AT1 and AT2 receptors mediate proliferation and migration of porcine vascular smooth muscle cells. American Journal of Physiology. Heart and Circulatory Physiology 301 H746-H756. (doi:10.1152/ajpheart.00431.2010)

Luo XH, Guo LJ, Xie H, Yuan LQ, Wu XP, Zhou HD \& Liao EY 2006 Adiponectin stimulates RANKL and inhibits OPG expression in human osteoblasts through the MAPK signaling pathway. Journal of Bone and Mineral Research 21 1648-1656. (doi:10.1359/jbmr.060707)

Matsuda M, Shimomura I, Sata M, Arita Y, Nishida M, Maeda N, Kumada M, Okamoto Y, Nagaretani H, Nishizawa H et al. 2002 Role of adiponectin in preventing vascular stenosis. The missing link of adipo-vascular axis. Journal of Biological Chemistry 277 37487-37491. (doi:10.1074/jbc. M206083200)

Mistry T, Digby JE, Desai KM \& Randeva HS 2008 Leptin and adiponectin interact in the regulation of prostate cancer cell growth via modulation of p53 and bcl-2 expression. BJU International 101 1317-1322. (doi:10.1111/ j.1464-410X.2008.07512.x)

Mohankumar SK, Taylor CG, Siemens L \& Zahradka P 2012 Activation of phosphatidylinositol-3 kinase, AMP-activated kinase and Akt substrate$160 \mathrm{kDa}$ by trans -10 , cis- 12 conjugated linoleic acid mediates skeletal muscle glucose uptake. Journal of Nutritional Biochemistry. In press. (doi:10.1016/j.jnutbio.2012.01.006)

Motoshima H, Goldstein BJ, Igata M \& Araki E 2006 AMPK and cell proliferation - AMPK as a therapeutic target for atherosclerosis and cancer. Journal of Physiology 574 63-71. (doi:10.1113/jphysiol.2006.108324)

Nagata D, Takeda R, Sata M, Satonaka H, Suzuki E, Nagano T \& Hirata Y 2004 AMP-activated protein kinase inhibits angiotensin II-stimulated vascular smooth muscle cell proliferation. Circulation 110 444-451. (doi:10.1161/01.CIR.0000136025.96811.76)
Nakayama S, Miyoshi Y, Ishihara H \& Noguchi S 2008 Growth-inhibitory effect of adiponectin via adiponectin receptor 1 on human breast cancer cells through inhibition of S-phase entry without inducing apoptosis. Breast Cancer Research and Treatment 112 405-410. (doi:10.1007/s10549007-9874-3)

Nishimura M, Hashimoto T, Kobayashi H, Yamazaki S, Okino K, Fujita H, Inoue N, Takahashi H \& Ono T 2006 Association of the circulating adiponectin concentration with coronary in-stent restenosis in haemodialysis patients. Nephrology, Dialysis, Transplantation 21 1640-1647. (doi:10.1093/ndt/gfk088)

Noto A, Zahradka P, Yurkova N, Xie X, Nitschmann E, Ogborn M \& Taylor CG 2006 Conjugated linoleic acid reduces hepatic steatosis, improves liver function, and favorably modifies lipid metabolism in obese insulinresistant rats. Lipids 41 179-188. (doi:10.1007/s11745-006-5086-6)

Ogunwobi OO \& Beales IL 2006 Adiponectin stimulates proliferation and cytokine secretion in colonic epithelial cells. Regulatory Peptides $\mathbf{1 3 4}$ 105-113. (doi:10.1016/j.regpep.2006.02.001)

Ogunwobi OO \& Beales IL 2008 Globular adiponectin, acting via adiponectin receptor-1, inhibits leptin-stimulated oesophageal adenocarcinoma cell proliferation. Molecular and Cellular Endocrinology 285 43-50. (doi:10.1016/j.mce.2008.01.023)

Okamoto Y, Kihara S, Ouchi N, Nishida M, Arita Y, Kumada M, Ohashi K, Sakai N, Shimomura I, Kobayashi H et al. 2002 Adiponectin reduces atherosclerosis in apolipoprotein E-deficient mice. Circulation 106 2767-2770. (doi:10.1161/01.CIR.0000042707.50032.19)

Palanivel R, Fang X, Park M, Eguchi M, Pallan S, De Girolamo S, Liu Y, Wang Y, Xu A \& Sweeney G 2007 Globular and full-length forms of adiponectin mediate specific changes in glucose and fatty acid uptake and metabolism in cardiomyocytes. Cardiovascular Research 75 148-157. (doi:10.1016/j.cardiores.2007.04.011)

Pfeiler GH, Buechler C, Neumeier M, Schaffler A, Schmitz G, Ortmann O \& Treeck O 2008 Adiponectin effects on human breast cancer cells are dependent on 17- $\beta$ estradiol. Oncology Reports 19 787-793.

Sato J, Nair K, Hiddinga J, Eberhardt NL, Fitzpatrick LA, Katusic ZS \& O'Brien T 2000 eNOS gene transfer to vascular smooth muscle cells inhibits cell proliferation via upregulation of p27 and p21 and not apoptosis. Cardiovascular Research 47 697-706. (doi:10.1016/S0008-6363 (00)00137-1)

Saward L \& Zahradka P 1997a Angiotensin II activates phosphatidylinositol 3-kinase in vascular smooth muscle cells. Circulation Research 81 249-257. (doi:10.1161/01.RES.81.2.249)

Saward L \& Zahradka P $1997 b$ Coronary artery smooth muscle in culture: migration of heterogeneous cell populations from vessel wall. Molecular and Cellular Biochemistry 176 53-59. (doi:10.1023/A:1006870827516)

Scherer PE, Williams S, Fogliano M, Baldini G \& Lodish HF 1995 A novel serum protein similar to $\mathrm{C} 1 \mathrm{q}$, produced exclusively in adipocytes. Journal of Biological Chemistry 270 26746-26749. (doi:10.1074/jbc.270. 45.26746)

Schmid PM, Resch M, Steege A, Fredersdorf-Hahn S, Stoelcker B, Birner C, Schach C, Buechler C, Riegger GA, Luchner A et al. 2011 Globular and full-length adiponectin induce NO-dependent vasodilation in resistance arteries of Zucker lean but not Zucker diabetic fatty rats. American Journal of Hypertension 24 270-277. (doi:10.1038/ajh.2010.239)

Schraw T, Wang ZV, Halberg N, Hawkins M \& Scherer PE 2008 Plasma adiponectin complexes have distinct biochemical characteristics. Endocrinology 149 2270-2282. (doi:10.1210/en.2007-1561)

Takeuchi T, Adachi Y, Ohtsuki Y \& Furihata M 2007 Adiponectin receptors, with special focus on the role of the third receptor, T-cadherin, in vascular disease. Medical Molecular Morphology 40 115-120. (doi:10.1007/s00795007-0364-9)

Trayhurn P \& Bing C 2006 Appetite and energy balance signals from adipocytes. Philosophical Transactions of the Royal Society of London. Series B: Biological Sciences 361 1237-1249. (doi:10.1098/rstb.2006.1859)

Tsao TS, Murrey HE, Hug C, Lee DH \& Lodish HF 2002 Oligomerization state-dependent activation of NF-kappa B signaling pathway by adipocyte complement-related protein of $30 \mathrm{kDa}$ (Acrp30). Journal of Biological Chemistry 277 29359-29362. (doi:10.1074/jbc.C200312200) 
Waki H, Yamauchi T, Kamon J, Ito Y, Uchida S, Kita S, Hara K, Hada Y, Vasseur F, Froguel P et al. 2003 Impaired multimerization of human adiponectin mutants associated with diabetes. Molecular structure and multimer formation of adiponectin. Journal of Biological Chemistry 278 40352-40363. (doi:10.1074/jbc.M300365200)

Waki H, Yamauchi T, Kamon J, Kita S, Ito Y, Hada Y, Uchida S, Tsuchida A, Takekawa S \& Kadowaki T 2005 Generation of globular fragment of adiponectin by leukocyte elastase secreted by monocytic cell line THP-1. Endocrinology 146 790-796. (doi:10.1210/en.2004-1096)

Wang Y, Lam KS, Xu JY, Lu G, Xu LY, Cooper GJ \& Xu A 2005 Adiponectin inhibits cell proliferation by interacting with several growth factors in an oligomerization-dependent manner. Journal of Biological Chemistry 280 18341-18347. (doi:10.1074/jbc.M501149200)

Weyer C, Funahashi T, Tanaka S, Hotta K, Matsuzawa Y, Pratley RE \& Tataranni PA 2001 Hypoadiponectinemia in obesity and type 2 diabetes: close association with insulin resistance and hyperinsulinemia. Journal of Clinical Endocrinology and Metabolism 86 1930-1935. (doi:10.1210/jc.86. 5.1930)

Yamauchi T, Kamon J, Minokoshi Y, Ito Y, Waki H, Uchida S, Yamashita S, Noda M, Kita S, Ueki K et al. 2002 Adiponectin stimulates glucose utilization and fatty-acid oxidation by activating AMP-activated protein kinase. Nature Medicine 8 1288-1295. (doi:10.1038/nm788)

Yamauchi T, Kamon J, Ito Y, Tsuchida A, Yokomizo T, Kita S, Sugiyama T, Miyagishi M, Hara K, Tsunoda M et al. 2003a Cloning of adiponectin receptors that mediate antidiabetic metabolic effects. Nature 423 762-769. (doi:10.1038/nature01705)
Yamauchi T, Kamon J, Waki H, Imai Y, Shimozawa N, Hioki K, Uchida S, Ito Y, Takakuwa K, Matsui J et al. 2003 b Globular adiponectin protected ob/ob mice from diabetes and ApoE-deficient mice from atherosclerosis. Journal of Biological Chemistry 278 2461-2468. (doi:10.1074/jbc.M209033200)

Yau L, Litchie B, Thomas S, Storie B, Yurkova N \& Zahradka P 2003 Endogenous mono-ADP-ribosylation mediates smooth muscle cell proliferation and migration via protein kinase $\mathrm{N}$-dependent induction of c-fos expression. European Journal of Biochemistry 270 101-110. (doi:10.1046/j.1432-1033.2003.03366.x)

Yu BP, Hong CC, Sachidanandan C, Babitt JL, Deng DY, Hoyng SA, Lin HY, Bloch KD \& Peterson RT 2008 Dorsomorphin inhibits BMP signals required for embryogenesis and iron metabolism. Nature Chemical Biology 4 33-41. (doi:10.1038/nchembio.2007.54)

Zahradka P \& Ebisuzaki K 1984 Poly(ADP-ribose) polymerase is a zinc metalloenzyme. European Journal of Biochemistry 142 503-509. (doi:10.1111/j.1432-1033.1984.tb08314.x)

Zhu W, Cheng KK, Vanhoutte PM, Lam KS \& Xu A 2008 Vascular effects of adiponectin: molecular mechanisms and potential therapeutic intervention. Clinical Science 114 361-374. (doi:10.1042/CS20070347)

Received in final form 19 July 2012

Accepted 2 August 2012

Made available online as an Accepted Preprint 2 August 2012 